\title{
Benchmarking the Life Cycle Cost Management of Building Project
}

\author{
Guoqiang Ren Qianying Zhang \\ Management School, Tianjin University of Technology, Tianjin 300384, P.R.China
}

\begin{abstract}
This paper firstly analysis the barriers of LCCM and finds that the important barriers are history data collection and application in the view of technique, thus the ideas of benchmark management can be used in LCCM effectively. Then it gives the cost benchmark set of LCCM. We use three methods to construct the cost benchmark set of LCCM: selecting a benchmark project, combining a virtual benchmark project from several projects, using Artificial Neural Network method. Finally the steps are given to control the life cycle cost of building project using the cost benchmark set of LCCM.
\end{abstract}

Keywords: Life cycle cost management, Benchmarking, Building project, Cost benchmark set, Artificial neural networks

\section{Introduction}

In recent years, life cycle cost management (LCCM) theory of building project has got great development. But the development focus on life cycle costing theory, the literature about life cycle cost control is not enough. The US Building Research Board Committee thinks that life cycle cost (LCC) can be controlled, and gives the methods to achieve LCC control, they are establishing LCCM manuals, LCCM as a basic policy, establishing LCCM system, using value engineering etc. [1]. The Federal Facilities Council analyses the key factors in order to control LCC in each phase of building project life cycle, and gives the impaction of Value Engineering to LCC in decision phase, design phase and construction phase [2]. OPET analyses the objectives and possibilities of LCCM, and gives the contents and methods in every phase of the building project and in different contract types [3]. The above researches can't use in practice effectively and lack theory base because of its simple relatively.

Benchmarking is an useful tool, based on a belief that it is possible to identify and examine the best practices of other organizations and then initiate constructive changes in one's own organization, derived from these observations. But the construction industry seems to be slow (if not reluctant) to adopt this tool. E. Palaneeswaran \& M.M. Kumaraswamy thinks that the reasons for this may stem from: (a) the complex nature of construction operations; (b) the uniqueness of and changing project environments; (c) shorter project life spans; (d) rapid changes in the structure and composition of construction teams; (e) intense competition within the same group, e.g. contractors; (f) adversarial roles assigned to different groups, e.g. between consultants and contractors [4]. Only a very few construction-benchmarking studies have been documented. While Walker and Sidwell employed the benchmarking methodology and identified key factors affecting construction time performance in the preparation of the benchmarking manual [5], Chan and Chan benchmarked construction time performance in the Hong Kong setting [6]. Moreover, Chan et al. explored CSFs for partnering in construction projects [7].

The theory and method of benchmark management can be used in LCCM of building project in the paper. LCC benchmark established in every phase of the building project can be used as the object of LCC control to control the LCC for a similar type of building project.

\section{The barriers of LCCM}

The idea that life-cycle costs can be controlled and minimized has wide appeal, but life-cycle cost management has not been consistently applied in the phase of design and management of building. There are two main problems that discourage use of life-cycle cost. One is the shortage of reliable information on historical costs and performance, which is needed for accurate estimation of costs. Another is that there isn't an effective LCC control method.

\subsection{The shortage of reliable historical data}

Firstly, buildings are dissimilar, located in different areas, built at different times, and operated by a variety of owners and their agents. Cost data are therefore difficult to collect and analyze; Secondly, there is no institutional mechanism and Standard Method for Collecting and Recording of Data; Thirdly, the accounting systems used by building managers and contractors seldom make it possible to 
identify accurately the costs of maintenance and repair of specific components of single building; Fourthly, it's difficult to predict the future O\&M cost and performance because of the uncertainty in the building's life cycle; Fifthly, it's difficult to get the assumption parameters actually used in the life-cycle cost analysis-such as economic life and discount rate. Finally, the level of effort required in analysis increases rapidly as the number and range of alternatives increase.

\subsection{The shortage of effective LCC control method}

Even if there are many reliable historical data, we can't control LCC of construction project effectively. The methods used now are mainly used to compare the cost and performance passively has been happened. It's shortage of an effective controlling goal and the method to approaching the goal.

The benchmarking method gives us a method how to construction a LCC benchmark as the control goal and control the LCC using the LCC benchmark.

\section{The basic of benchmarking LCCM of building project}

\subsection{The definition of LCC benchmark}

Australia Government Department of Defense gives the definition of project cost benchmark as follows [8]:

A PCB is an estimate of the whole of life cost of delivering a capability where Defense buys the capital equipment and facilities and then supports on-going delivery of the service needed to provide that capability. The estimate should be based on the most cost effective method and may include the use of outsourced maintenance and service delivery.

According to above definition and combining with the characteristics of building project, we give the definition of LCC benchmark as follows:

A LCC benchmark is cost set relative to the LCC of building project that is got from the LCC history data of building project. It should be based on the most cost effective method and may include the use of outsourced LCC data. It can be the goal of LCC control and supports the LCC control of a proposed project. The process of getting LCC benchmark is an optimizing process continually with the more and more LCC history data can be got.

The cost structure of LCC benchmark will be discussed in the following section.

\subsection{The LCC benchmark of building project}

The LCC of building project is consisted of Capital cost, O\&M cost and disposal cost. Because the future O\&M activities are different in different years, we get two types of O\&M cost: annual recurring costs, non-annual recurring costs. The proposed LCC benchmark is divided into four levels, the top-down hierarchy of LCC benchmark (see figure 1) is: Project level, Phase level, Category level, Element level.

A brief description of the composition of each level of the LCC benchmark is given below:

The project level is the highest level of LCC benchmark. For each building, there are three phases in its life: Capital cost, O\&M cost and disposal cost. Each Phase can be divided into its cost category. Capital can be divided into Land acquisition cost, design cost etc. as shown in Fig.1; O\&M cost can be divided into annual recurring costs and non-annual recurring costs; Disposal cost can be divided into four cost category as shown in figure 1. Construction cost, annual recurring costs and non-annual recurring costs can be divided into their cost element respectively.

\subsection{The phase of building project life cycle}

The idea of LCC management can be used in every phase of construction project life cycle, and earlier using this method will get more save of LCC [9]. So LCC benchmark management method can be used in every phase of construction project life cycle. Project life cycle can be divided into different phase in different literature, and we think it should be divided into decision phase, design phase, construction phase, and O\&M phase.

LCC control of building project based benchmark management can be divided into two processes: construction LCC benchmark, control LCC using LCC benchmark.

\section{The construction process of LCC benchmark}

The construction process of LCC benchmark can be divided into four steps: project classify; data collection; data treatment; LCC benchmark computing (see Fig.2). 


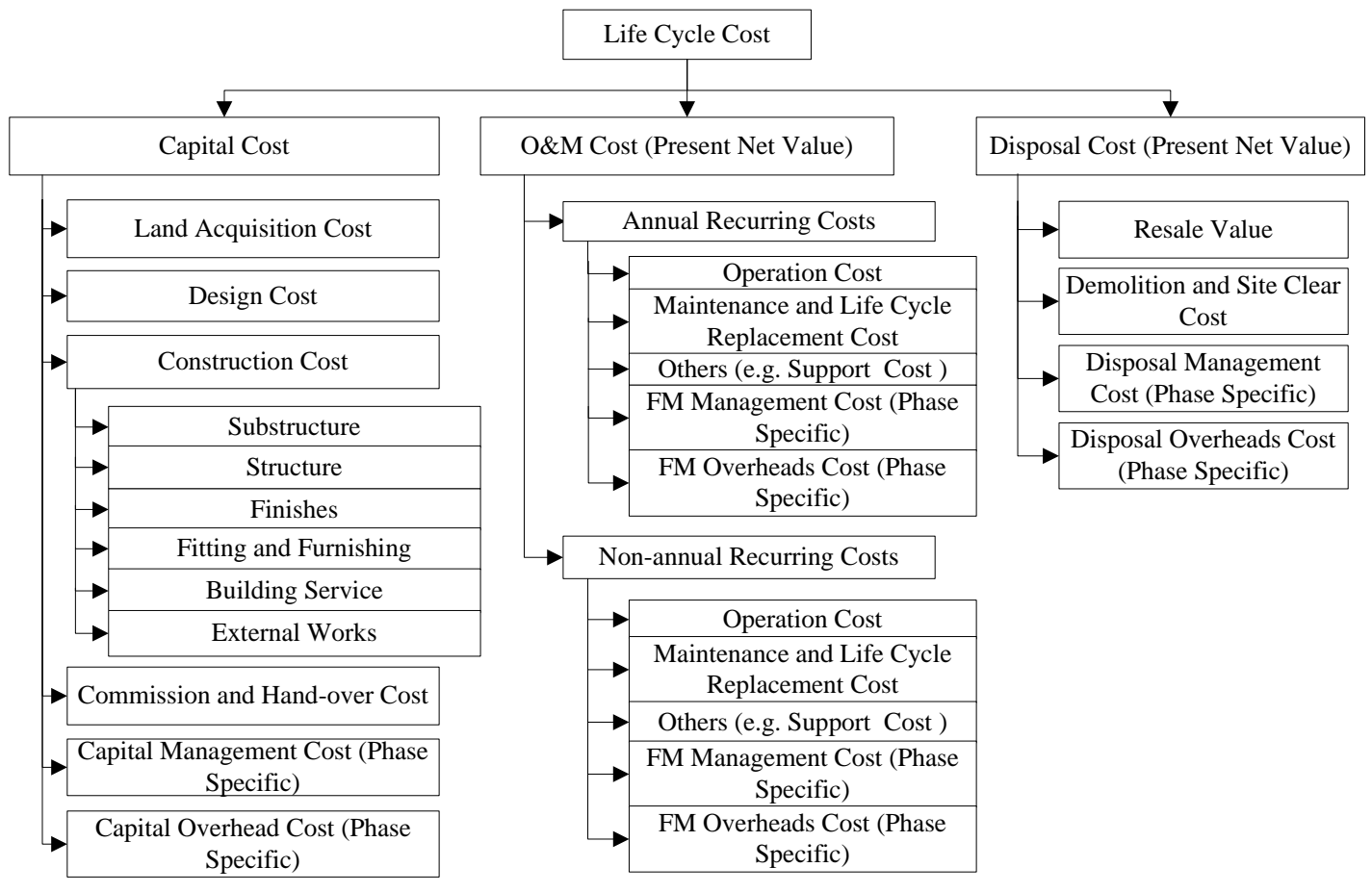

Fig.1: The structure of LCC benchmark.

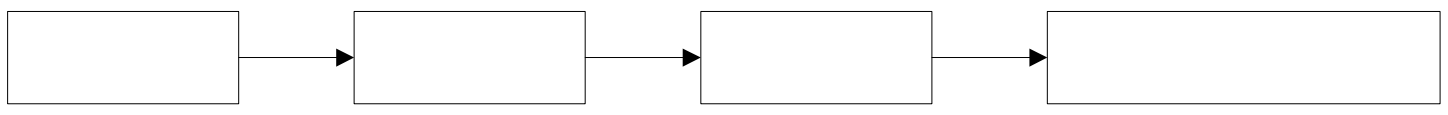

Fig.2: The construction process of LCC benchmark.

\subsection{Project classifies}

The first task of the construction process of LCC benchmark is to classify the project according to a unified standard. The standard should not be too detailed and too rough. If too detailed, we can't find one similar project. If too rough, the similar project will be more enough to apply in the computing of LCC benchmark, but it's doubtable of similar project's comparability. First selection is the type of building, such as schools, hospitals, dwelling houses, offices etc. Then the standard should be given according to the structure of building, such as substructure, structure, furnish, fitting etc.

\subsection{Data collection}

Data for LCC management are available from three main sources: specialist manufacturers, suppliers and contractors; modeling techniques; historical data.

Specialist manufacturers and suppliers can be expected to have detailed knowledge of the performance characteristics of their materials and components. Government cost management department have the responsibility of checkup project budget, especially public project. Thus it will give us some information about construction cost and O\&M cost; the models can then be used to analyze the whole life implications of particular design decisions or choices of materials. As an example, the majority of cleaning costs in a commercial building will be incurred in cleaning walls, floors and windows; Historical data sources of building project will produce profiles of initial costs and running costs, though they are likely to be very different even for the same type facility. We should develop a standard to collect these LCC data and information, the five level cost structure of building project LCC given by Mohamed A.EL-Haram etc may be a valuable reference [10]. These LCC historical data should be the main base data using in the construction of LCC benchmark.

\subsection{Data treatment}

Data treatment includes data adjustment and LCC computing two steps.

\subsubsection{Data adjustment}


Because the time, location, size, types etc of building project are different, thus they must be adjusted.

1) Adjustment for Location

Equation (1) is to be used to adjust the previous projects cost data for the City Cost Index.

$$
C_{A}=C_{N}\left(\frac{I_{A}}{I_{N}}\right)
$$

Where $C_{A}=$ cost in dollars for city $\mathrm{A} ; C_{N}=$ national average cost in dollars; $I_{A}=$ index for city $\mathrm{A} ; I_{N}=$ index based on the major city.

2) Adjustment for Time (Inflation)

We can use equation (2), which uses the change in value of an index between two years, to calculate an equivalent interest rate.

$$
\left(\frac{I_{\text {current }}}{I_{\text {reference }}}\right)=(1+i)^{n}
$$

Where $\mathrm{n}=$ number of years between current and reference year; $I_{\text {current }}=$ index for current year; $I_{\text {reference }}=$ index for reference year; $\mathrm{i}=$ equivalent interest rate

3) Adjustment for Size

The use of cost information from a previous project to forecast the cost of future projects has to be adjusted for the difference in size between two projects [11].

4) Adjustment for Height, Exterior Wall and Structure Type

Based on the classification given by Meyer and Burns these adjustments are for optional parameters. Using such parameters can enhance the accuracy and efficiency of the proposed system [12].

\subsubsection{LCC computing}

The above cost data getting through collection and adjustment may be construction cost, O\&M cost and disposal cost or their cost element through farther breakdown. Thus we must computing LCC of building project according to the existing data. Mathematic model of LCC computing has development by many scholars. Here we using the model by [13].

$$
\begin{gathered}
L C C=C_{0}+P W A \times \sum_{j=1}^{n a r} A_{j}+\sum_{k=1}^{n n r} C_{k} \times P W N_{k}-P W S \times S \\
\text { Where } P W A=\frac{1}{r}(1-(1+r))^{-T} \\
P W S=(1+r)^{-T} \\
P W N_{k}=\frac{1-(1+r)^{-n_{k} f_{k}}}{(1+r)^{f_{k}-1}}
\end{gathered}
$$

$$
n_{k}=\left\{\begin{array}{l}
\operatorname{int}\left(T / f_{k}\right), \operatorname{rem}\left(T / f_{k}\right)=0 \\
T / f_{k}-1, \text { elsewhere }
\end{array}\right.
$$

$C_{0}$-Initial costs; $A_{j}$-Annual recurring costs; $C_{k}$-Non-annual recurring costs; $S$-Disposal cost; $T$-Analysis Period; $r$-Discount rate.

\subsection{LCC benchmark computing}

There are three methods computing LCC benchmark of building project: select a benchmark project; building a virtual; computing by Mathematic model.

\subsubsection{Select a benchmark project}

In common case, we usually select a project from many similar projects as the benchmark project of this class project. The project selection should consider the following factors:

1) Cost effective project

Because the special characteristics of the project, e.g. size, type, structure and budget, it's difficult for us to decide which project is a success project as the benchmark project according to LCC minimizing principles. Thus we use LCC management check list to decide which project can be the benchmark project. The check list includes three parts as follows:

- Resource consumption

Resource includes electricity, gas and water. A good project should have the better resource saving effect. Thus the LCC management goal can be achieved through reducing the resource cost in the life cycle of building project.

- Indoor climate

Indoor climate includes Quality of indoor air, Thermal conditions, Lighting, Sound. A good project should make people feel better in the room. The indoor air shouldn't do any harm to people's health. Natural light should be used as more as possible because people feel better in natural light than in artificial light. Sound insulation effect should be given effectively, so that the outdoor noise and indoor noise don't disturb the people inside the building.

- Use of building

Use of building includes flexibility, common space and durability. A project with long life cycle, multipurpose and durability of materials and components will have lower LCC.

2) Location

Location of benchmark project shouldn't be in hinterland, at least in middle or big city. The difference between places will bring the great difference between labor cost, material cost and equipment cost respectively. Thus LCC of different place will have great difference.

3) Size 
The size of benchmark project shouldn't be too big or small. That kind of project is lack of universality because many projects have middle size.

The advantage of selecting a project as the LCC benchmark project is easy. But the project is difficult to fit the goal of LCC management because it has some limitation more or little. Thus we can use the virtual project integrating the advantages of all similar projects as the LCC benchmark project.

\subsubsection{Construct a virtual benchmark project}

Firstly, the performance optimization components must be found of every similar project relatively according to the goal of LCC optimization, such as one project is good at energy saving and another is good at indoor air etc. Secondly, the size and cost are adjusted of selected components. Thirdly, a virtual building project is generated by combining the selected components. In this process, we must ensure the reliability of generating process and accuracy of generating results. Thus we must not ensure repetition and confliction when we set component function.

The virtual LCC benchmark project generating by this method have more lower LCC as integrating advantages of many projects. But it's difficult to implement.

\subsubsection{Mathematic model}

Mathematic model, used in computing LCC benchmark of building project, includes two methods. One is Weighed Average Method. The other is Artificial Neural Networks method.

1) Weighed Average Method

Weighed average method can be expressed as follows:

$$
C_{p}=\sum_{i=1}^{n} w_{i} \times C_{i}
$$

Where n-similar project number; $C_{i}$-the ith project, same level, same name cost; $C_{p}$ - cost of this level LCC benchmark corresponding to all $C_{i} ; w_{i}$-the weights of ith project, weight can be the proposition of this project in the sum of all similar project or can be given by expert according to importance of project to LCC benchmark.

\section{2) Artificial Neural Networks method}

Artificial neural networks (ANNs) mimic, in a very simplified way, the human brain structure and functions. Neural networks are composed of interconnected elements called neurons or nodes. The neurons are organized in the form of layers. In the simplest architecture of an ANN, there is an input layer, one or more hidden layers, and an output layer (Fig. 3).

In an Ann, each neuron receives information from other neurons, processes it through an activation function, and produces output to other neurons. The output of a neuron $\mathrm{k}, y_{k}$, is given by:

$$
y_{k}=\left(\sum_{j=1}^{n} w_{k j} x_{j}+b_{k}\right)
$$

Where, $\mathrm{j}$ is the activation function, $x_{j}$ is the inputs to the neuron, $w_{k j}$ is the weights, and $b_{k}$ is an externally applied bias. Before an ANN can be used to perform its task, it should be trained to do so. This training or learning process is simply to determine the weights and biases using an appropriate learning algorithm.

First, we input building project information such as type, structure, size etc and LCC data of a certain level, usually level 4 or level 3 corresponding to the project in input layer. Then compute LCC data at same level of proposed project by BP method. Last, compute LCC benchmark by summing from level 4 to level 2 and compute LCC of project by using equation (3).

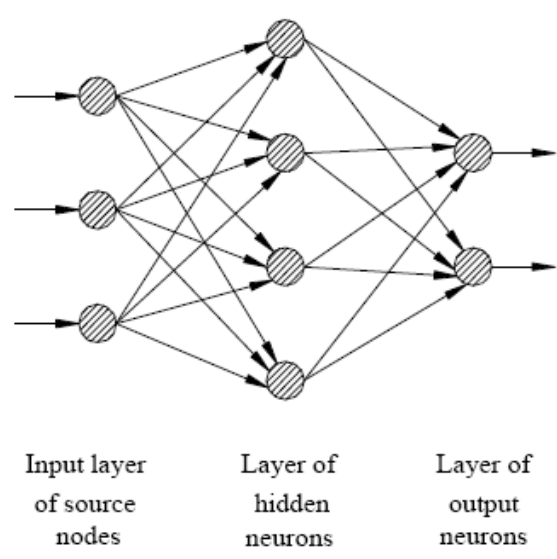

Fig.3: Artificial neural networks

Through above four steps, we can get the LCC benchmark in certain phase of building project life cycle. The life cycle of building project is divided into four phases. Then we get four LCC benchmark used in the control of LCC. Through the four LCC benchmark, we can find the change trend of LCC in the life cycle of building project and the cause bringing these change.

\section{The control process of LCC based LCC benchmark}

The control process of LCC based LCC benchmark can be divided into following steps:

1) Decide the error range

The LCC of proposed project must have some difference with the first level of LCC benchmark. 
This need us give a error range between LCC of proposed project and the first level of LCC benchmark, such as $\pm 5 \%$.If the relative error within this range, we think this LCC of proposed project can be accepted.

2) Compute LCC of proposed project

Through collecting cost data relative to LCC of proposed project, using LCC computing model shown as equation (3), we can computing the LCC data from level 4 to level 1 .

3) Adjust four level cost data of proposed project

The proposed project may have some difference with benchmark project. Thus it must be adjusted in time, location and size aspect etc according to the method description in 4.3.

4) Compare the cost data at same level

We first compare the LCC of proposed project with the first level of LCC benchmark. If the difference between LCC of proposed project and first level of LCC benchmark is within the permission range from lower limit to upper limit, we think that the LCC of proposed project will be acceptable and the alternative offering this LCC is a cost effective project alternative whose LCC should be optimization. Contrary if the difference is beyond the permission range, we will compare the cost data in the level 2 in order to find the reason bringing the difference. Then compare the cost data in the level 3 and level 4. Through above comparing, we can find all the limitations of project alternative, and then repeat the above process until the LCC's difference within the permission range.

\section{Conclusions}

Though the life cycle costing theory has been greatly developed, but how to control the LCC of building project hasn't been resolved effectively. The benchmark management theory is applied in the control process of LCC. The definition and cost structure of LCC benchmark have been given. The LCC control process is divided two steps: The construction process of LCC benchmark and the control process of LCC based LCC benchmark. The above method has its theory base and can be used in the practice of LCC control, which overcomes the limitations of traditional LCC management and will accelerate the applying of LCC management ideas in practice.

\section{Acknowledgement}

This work is supported by Science and Technology Development Foundation of Tinjin Higher Education (Grant No. 20042121).

\section{References}

[1] Building Research Board Committee, Pay now or pay later: controlling cost ownership from design through the service life of public buildings, NATIONAL ACADEMY PRESS, Washington D.C., 1991.

[2] THE FEDERAL FACILITIES COUNCIL AD TASK GROUP, SUSTAINABLE FEDERAL FACILITIES-A Guide to Integrating Value Engineering, Life-Cycle Costing, and Sustainable Development, FEDERAL FACILITIES COUNCIL REPORT NO.142,NATIONAL ACADEMY PRESS, Washington D.C.,2001.

[3] Motiva Oy, LCC Application Manual for Construction Clients and Project Managers, OPET report, 2004.

[4] E. Palaneeswaran \& M.M. Kumaraswamy, Benchmarking contractor selection practices in public-sector construction-a proposed model. Engineering, Construction and Architectural Management, 7(3):285-299, 2000.

[5] D.H.T. Walker and A.C. Sidwell, Benchmarking Engineering and Construction A Manual for Benchmarking Construction Time Performance, Construction Industry Institute Australia, Brisbane, 1996.

[6] A.P.C. Chan and D.W.M. Chan, A benchmark model for construction duration in public housing developments. International Journal of Construction Management, 3(1):11-14, 2003.

[7] A.P.C. Chan, D.W.M. Chan, Y.H. Chiang, B.S. Tang, E.H.W. Chan and K.S.K. Ho, Exploring critical success factors for partnering in construction projects. Journal of Construction Engineering and Management, 130(2):188-198, 2004.

[8] http://www.defence.gov.au/cfo/privfin/manual/ 04.htm

[9] S.J. Kirk and A.J. Dell'Isola, Life cycle costing for design professionals, McGrew-Hill Book Company, New York, 1995.

[10] Mohamed A. El-Haram, Sasa Marenjak and Malcom W.Horner, Development of a generic framework for collecting whole life cost data for the building industry. Journal of Quality in Maintenance Engineering, 8(2):144-151, 2002.

[11] R. L.Peurifoy, G.D. Oberlender, Estimating Construction Costs, 5th Edition, McGraw-Hill Companies, 2002.

[12] R. E.Meyer, J. T.Burns, Facility Parametric Cost Estimating. Transaction of the AACE 43rd Annual Meeting, pp. EST.02.1-EST.02.6, June 1999.

[13] M. Kishk. and A. Al-Hajj, A fuzzy model and algorithm to handle subjectivity in life cycle costing based decision making. Journal of Financial Management of Property and Construction, 5(1-2): 93-104, 2000. 